\title{
Analisis Performansi Konektifitas Pada Jaringan Wireless Broadband di Bandung
}

\section{OTNI EL TONAPA ${ }^{1}$, PAULI NE RAHMI ATI ${ }^{1}$, DEBORA KOMBA ${ }^{2}$}

1. Teknik Elektro Institut Teknologi Nasional

2. PT.Telkom Flexi 1 Bandung Selatan

Email : god_elona@live.com

\begin{abstract}
ABSTRAK
Perkembangan teknologi komunikasi Wireless mengarah ke teknologi yang berbasis jaringan IP (Internet Protocol). Access Point adalah suatu perangkat Wireless Router. Access point membentuk hot spot, sedangkan Wireless Router mengatur lalu lintas data. Parameter yang diukur pada penelitian ini yaitu Quality of Service (QoS), antara lain pengukuran jitter, delay, dan packet loss yang dihasilkan dalam layanan paket data. Nilai jitter rata-rata sesama pengguna modem ADSL yang terhubung dengan access point pada smartphone bernilai $143.36 \mathrm{~ms}$ sedangkan pada laptop berada pada nilai $45.6 \mathrm{~ms}$. Nilai jitter sesama penguna modem GPON, nilai rata-rata pada smartphone bernilai $133.12 \mathrm{~ms}$, sedangkan pada laptop berada pada nilai $45.56 \mathrm{~ms}$. Nilai rata-rata delay sesama pengguna modem ADSL pada smartphone bernilai $99.04 \mathrm{~ms}$, sedangkan pada laptop sebesar $56.33 \mathrm{~ms}$. Nilai rata-rata delay pada sesama pengguna modem GPON pada smartphone adalah $97.96 \mathrm{~ms}$ sedangkan pada laptop sebesar 56.15 ms. Packet loss dari hasil pengujian keduanya memiliki presentase sama yaitu $1 \%$.
\end{abstract}

Kata kunci: Teknologi Digital Subscriber Line, Jaringan Optik Pasif, Dynamic Host Configuration Protocol(DHCP), Quality of Service (QoS)

\begin{abstract}
Wireless communication technology development leading to technologies that network-based IP (Internet Protocol). Access Point Wireless Router is a device. Access point forming a hot spot, while the router manage data traffic. Parameters measured in this research is Quality of Service (QOS). among other things, measuring jitter, delay, and packet loss. resulting in packet data service. Jitter value among ADSL fellow have the average on smartphones $143.36 \mathrm{~ms}$. On laptop average be at $45.6 \mathrm{~ms}$. While jitter value among GPON fellow user have the average on smartphone $133.12 \mathrm{~ms}$. On laptop average be at $45.56 \mathrm{~ms}$. The average value of the delay to ADSL fellow users on smartphones $99.04 \mathrm{~ms}$ and on laptop average be at $56.33 \mathrm{~ms}$. While delay value among GPON fellow user have the average on smartphone $97.96 \mathrm{~ms}$ while on laptop average be $56.15 \mathrm{~ms}$. Packet loss from the test results, both have the same percentage of $1 \%$.
\end{abstract}

Keywords: Asymmetric Digital Subscriber Line (ADSL), Gigabyte Passive Optical Network (GPON), Dynamic Host Configuration Protocol (DHCP), Quality of Service (QOS) 


\section{PENDAHULUAN}

Perkembangan teknologi telekomunikasi yang semakin pesat, baik sarana maupun prasarananya, menjadikan kebutuhan masyarakat akan pelayanan jasa dalam bidang telekomunikasi pun ikut berkembang dari waktu ke waktu baik secara kualitas, kuantitas maupun jenisnya. Teknologi wireless merupakan teknologi di bidang telekomunikasi yang menawarkan kemudahan dibandingkan teknologi wired atau dengan media kabel. Teknologi ini memiliki kelebihan dengan menawarkan fleksibilitas kepada user, sehingga user dapat berpindah-pindah tempat tanpa perlu mencari koneksi kabel selama masih ada dalam jangkauan sinyal wireless tersebut.

Kebutuhan akan koneksi internet yang murah dan dimana saja juga menjadi tuntutan di lingkungan sekitar, oleh karena itu teknologi wireless merupakan jawaban yang tepat untuk permasalahan tersebut. Untuk implementasinya, dibutuhkan suatu jaringan yang berbasis wireless yaitu dengan menggunakan sistem Access Point. Dengan menggunakan access point, user bisa lebih mudah untuk terhubung terhadap jaringan LAN kabel secara wireless.

Komunikasi wireless dengan menggunakan access point ini melayani tidak hanya dalam komunikasi data atau internet, melainkan juga layanan lainnya pada komunikasi $3 \mathrm{G}$ offlloading, VPN (Virtual Privat Network), dan EDC (Electronic Data Capture). Layananlayanan tersebut merupakan implementasi bidang telekomunikasi yang digunakan melalui jaringan IP maupun MAC Address dengan sistem access point dalam proses pengiriman paket data ke masing-masing user/client. Dimana teknologi untuk komunikasi data dapat dilakukan melalui jaringan wireless broadband.

\section{METODOLOGI}

\subsection{Perancangan Sistem}

Untuk menganalisa performasi konektifitas jaringan wireless broadband berbasis NMS (Network Management System) yang telah terkoneksi dengan access point. Diharuskan user bisa berkomunikasi dengan jaringan pada access point, maka terlebih dahulu dirancang pembangunan infrastruktur untuk server baik untuk modem ADSL (Asymmetric Digital Subscriber Line) dan modem GPON (Gigabyte Passive Optical Network), serta komunikasi antar client server yang ada pada flowchart Gambar 1: 
Tonapa, dkk

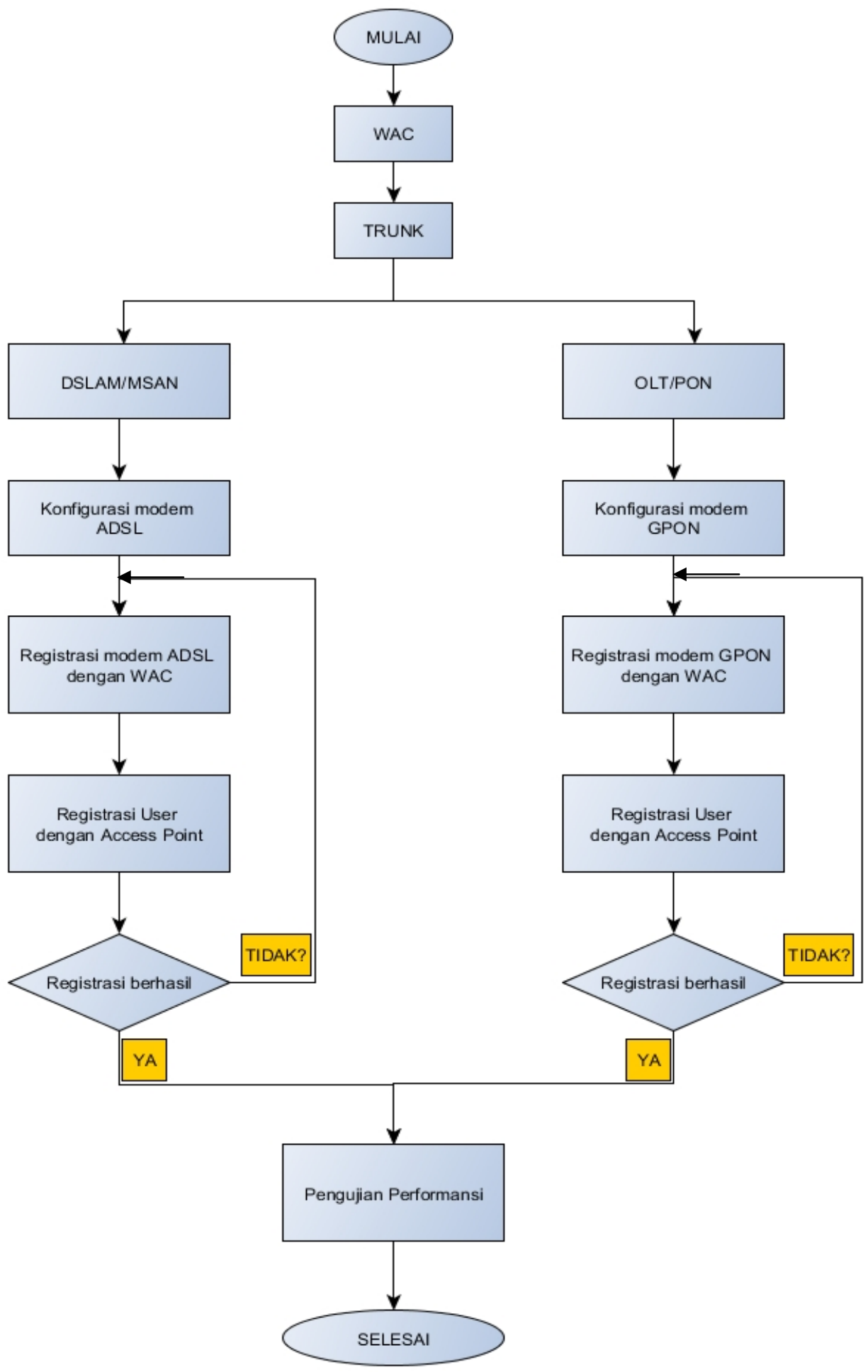

Gambar 1. Flowchart perancangan sistem 
Sebelum merealisasikan kedua jaringan tersebut, diperlukan software dan hardware yang memadai. Setelah proses instalasi dikedua modem tersebut berhasil, maka dilakukan konfigurasi jaringan. Konfigurasi jaringan disini meliputi registrasi user, konfigurasi user dan jaringan modem itu sendiri (Speedy maupun Telkom Access). Bila proses registrasi gagal, maka dilakukan pemeriksaan ulang pada bagian konfigurasi modem. Setelah proses registrasi berhasil, maka dilanjutkan dengan pengujian performansi untuk kedua modem. Pengujian performansi QoS mencakup jitter, delay, dan packet loss.

\subsection{Desain Topologi J aringan}

Desain jaringan Wireless Broadband yang akan diimplementasikan melalui access point pada modem ADSL dan modem GPON berupa layanan paket data. Adapun komponen-komponen yang menyusun sistem ini adalah modem ADSL dan modem GPON yang diintegrasikan dengan access point dengan perolehan IP (Internet Ptotocol) address secara acak atau dengan system DHCP (Dynamic Host Configuration Protoco) yang berbasiskan NMS (Network Management System). Untuk implementasi jaringan, maka skenario desain jaringan diterapkan seperti Gambar 2 :

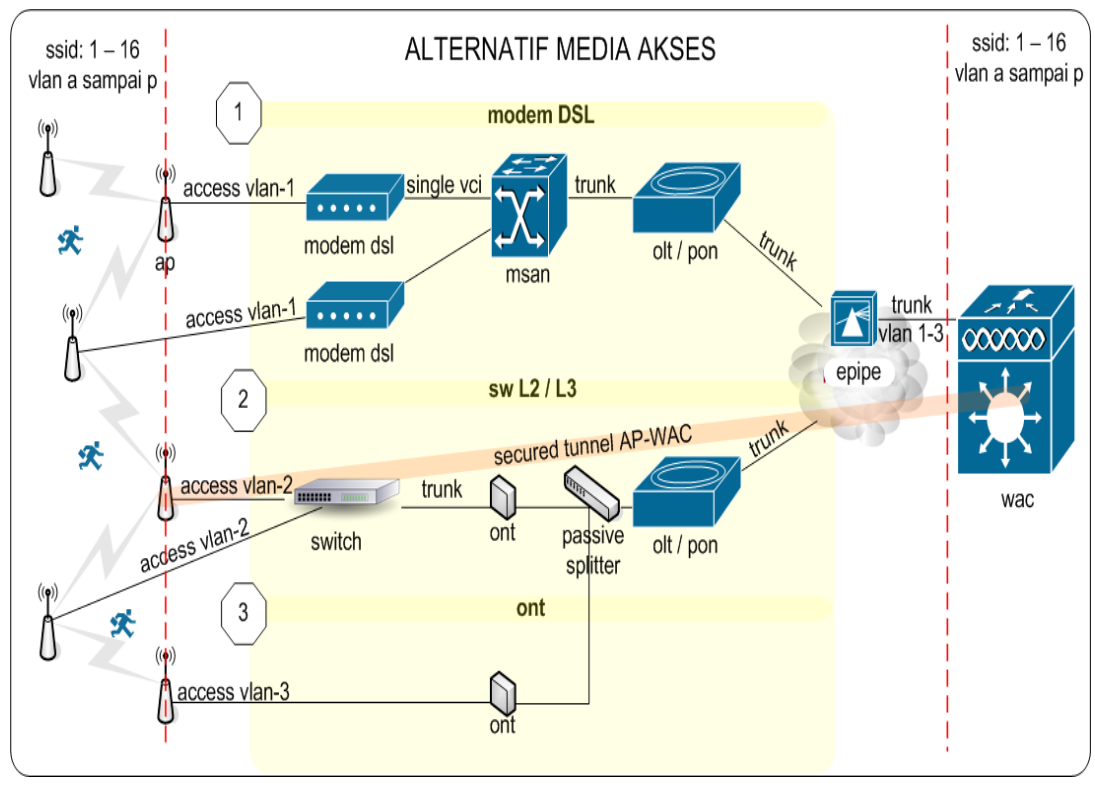

Gambar 2. Desain topologi jaringan

Kedua modem baik ADSL maupun GPON terhubung dengan access point, selanjutnya access point ini akan terhubung dengan user melalui media wireless. User disini menggunakan smartphone dan laptop.

\subsection{Spesifikasi sistem}

Dalam penelitian ini untuk pengoperasian sistem komputer untuk membangun sistem jaringan diperlukan perangkat keras dan perangkat lunak yang memiliki spesifikasi yang memadai. Perangkat keras yang digunakan untuk pengoperasian modem ADSL dan GPON adalah sistem komputer dengan spesifikasi pada Tabel 1 sebagai berikut : 
Tabel 1. Spesifikasi sistem perangkat keras server

\begin{tabular}{|c|c|c|c|}
\hline No & Peralatan & Unit & Keterangan \\
\hline 1 & Laptop & 1 & $\begin{array}{l}\text { - Prosesor CPU Intel(R) core (TM) i5-3210M } \\
\text { CPU 540 2.5 GHz } \\
\text { - VGA NVidia Corporation GT640 [GeForce Cuda] } 2 \\
\text { GB } \\
\text { - Sound Card NVidia Corporation High Definition } \\
\text { Audio Controller } \\
\text { - Network Card Ethernet Realtek Ethernet } \\
\begin{array}{l}\text { Realtek RTL8111E chip (10/100/1000 Mbps) } \\
\text { - HDD SATA } 750 \text { GB }\end{array}\end{array}$ \\
\hline 2 & OS & 1 & Windows 8 \\
\hline
\end{tabular}

Perangkat keras yang digunakan pada sistem komputer untuk client sebagai user agent. Pada client ADSL maupun GPON, digunakan 2 client yang berbeda, yaitu laptop dan smartphone. Berikut adalah spesifikasi pada Tabel 2:

Tabel 2. Spesifikasi sistem perangkat keras client

\begin{tabular}{|c|l|c|l|}
\hline No & \multicolumn{1}{|c|}{ Peralatan } & Unit & \multicolumn{1}{c|}{ Keterangan } \\
\hline 1 & User 1 (Laptop) & 1 & $\begin{array}{l}\text { Prosesor Intel(R) core (TM) i5-3317U, CPU @1.70 } \\
\text { GHz } \\
\text { RAM 4 GB DDR3 } \\
\end{array}$ \\
& & & $\begin{array}{l}\text { Networking card: Integrated 802.11 b/g/n } \\
\text { HDD 750 GB }\end{array}$ \\
\hline 2 & $\begin{array}{l}\text { User 2 } \\
\text { (Smartphone) }\end{array}$ & 1 & $\begin{array}{l}\text { Prosesor Dual-core 1 GHz Cortex-A9 } \\
\text { RAM 512 MB } \\
\text { Wi-Fi 802.11 b/g/n, Wi-Fi hotspot } \\
\text { Storage 16 GB }\end{array}$ \\
\hline
\end{tabular}

Berikut adalah perangkat lunak yang akan digunakan pada sistem komputer untuk membangun sistem jaringan broadband, tertera pada Tabel 3 dibawah ini:

Tabel 3. Spesifikasi sistem perangkat lunak

\begin{tabular}{|c|l|l|}
\hline No & \multicolumn{1}{|c|}{ Nama perangkat lunak } & \multicolumn{1}{|c|}{ Keterangan } \\
\hline 1 & Ping & Aplikasi mengetahui aktifitas paket data \\
\hline 2 & Mozilla Firefox 24.0 & Web Browser \\
\hline 3 & inSSIDer & $\begin{array}{l}\text { Aplikasi untuk mendeteksi jaringan Wireless terdekat } \\
\text { modem GPON }\end{array}$ \\
\hline 5 & PuTTy & $\begin{array}{l}\text { Aplikasi untuk mendeteksi jaringan Wireless dan } \\
\text { Access Point }\end{array}$ \\
\hline 5 & Odyssey Access Client & $\begin{array}{l}\text { Aplikasi yang digunakan untuk memonitoring Packet } \\
\text { Loss }\end{array}$ \\
\hline
\end{tabular}




\subsection{Overview modem ADSL}

Merupakan satu dari beberapa jenis DSL (Digital Subcriber Line) modem dengan menggunakan teknologi asimetris. Dikatakan asimetris karena kapasitas kecepatan downlink pengguna lebih besar daripada kecepatan uplink-nya. Sistem ADSL ini dikombinasikan dengan akses yang selalu online yang menjadikan ADSL ideal untuk keperluan internet atau menjelajahi intranet. Komponen-komponen yang digunakan dalam penggunaan modem ADSL yaitu: Modem ADSL, Splitter, dan Telepon.

\subsection{Overview modem GPON}

GPON merupakan teknologi $F T T x$ yang dapat menngirimkan servis sampai ke pelanggan menggunakan kabel fiber optic. Jika sebelumnya pelanggan menggunakan kabel tembaga pada instalasi perkabelan di sisi pelanggan, maka sekarang instalasi perkabelan bisa menggunakan kabel optik. Keunggulannya adalah bandwidth yang ditawarkan bisa mencapai 2.488 Gbps (downstream) sampai pelanggan tanpa ada kehilangan bandwidth. Konfigurasi network GPON terdiri dari Optical Line Terminal (OLT), Optical Distribution Network (ODN), dan Optical Network Termination/Unit (ONT/ONU). Jadi FTTH (Fiber To The Home) ataupun FTTB (Fiber To The Building) merupakan skema yang pas untuk GPON. ONT hanya berukuran sebesar modem ADSL, mengantarkan layanan broadband ke pelanggan. Interface ONT sendiri bisa dikombinasikan antara Fast Ethernet (FE), POTS, dan RF overlay tergantung keinginan pelanggan. Variasi ONT dengan tipe interface yang berbeda-beda ditawarkan oleh operator. Inilah salah satu fleksibilitas dari GPON.

\section{HASI L PENELITI AN DAN ANALISIS}

\subsection{Jitter}

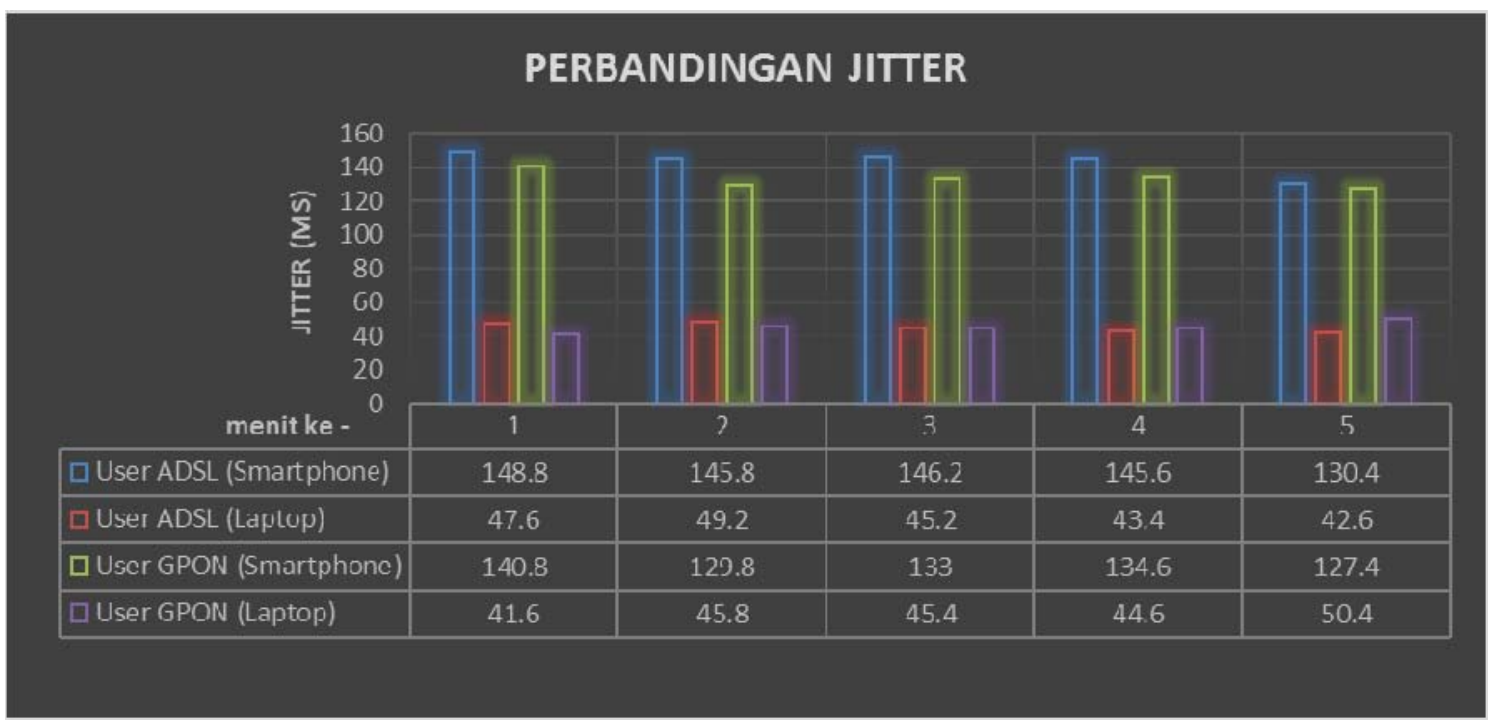

Gambar 3. Perbandingan jitter

Jitter, atau variasi kedatangan paket, hal ini diakibatkan oleh variasi-variasi dalam panjang antrian, dalam waktu pengolahan data, dan juga dalam waktu penghimpunan ulang paketpaket di akhir perjalanan jitter. Jitter lazimnya disebut variasi delay, berhubungan erat 
dengan latency, yang menunjukkan banyaknya variasi delay pada transmisi data di jaringan. Delay antrian pada router dan switch dapat menyebabkan jitter.

Besarnya nilai jitterakan sangat dipengaruhi oleh variasi beban trafik dan besarnya tumbukan antar paket (collision) yang ada dalam jaringan IP. Semakin besar beban trafik di dalam jaringan akan menyebabkan semakin besar pula peluang terjadinya kemacetan (congestion) paket data, dengan demikian nilai jitter-nya akan semakin besar.

Merujuk pada rekomendasi bahwa jitter yang memenuhi standar atau baik adalah kurang dari 75 ms (STD A-002-2004 VERSION 1.2). Untuk pengujian konektifitas jaringan pada modem ADSL nilai jitter rata-rata sesama pengguna yang terhubung dengan access point pada smartphone bernilai $143.36 \mathrm{~ms}$, sedangkan pada laptop berada pada nilai $45.6 \mathrm{~ms}$. Pengujian menggunakan modem GPON nilai jitter rata-rata pada smartphone sebesar 133.12 $m s$ dan pada laptop rata-rata berada pada nilai $45.56 \mathrm{~ms}$. Berdasarkan hasil pengujian tersebut, maka konektifitas pada modem ADSL lebih baik dari konektifitas pada modem GPON. Walaupun demikian, nilai rata-rata jitter pada modem GPON masih memenuhi standar yang telah direkomendasikan.

\subsection{Delay}

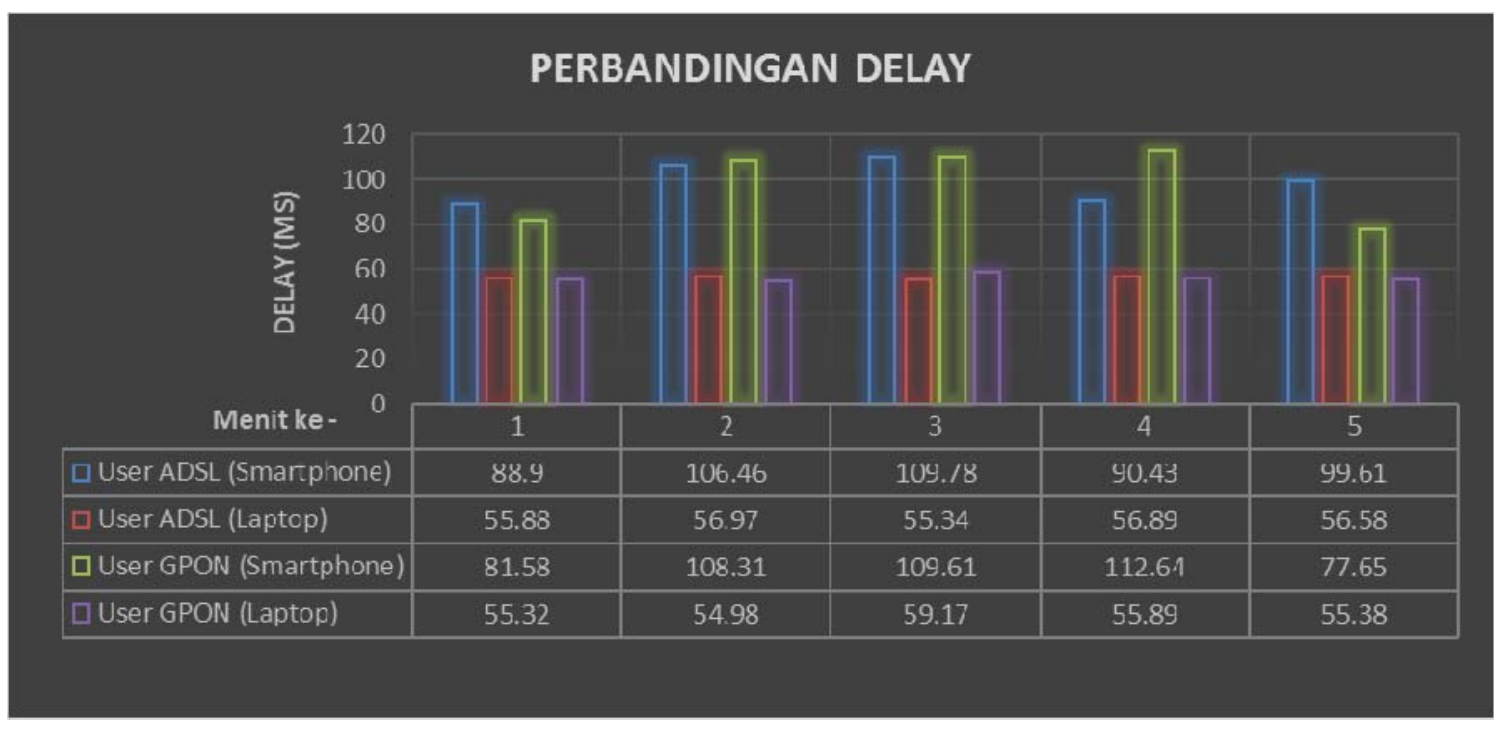

Gambar 4. Perbandingan delay

Delay (latency) merupakan waktu yang dibutuhkan data untuk menempuh jarak dari asal ke tujuan. Delay dapat dipengaruhi oleh jarak, media fisik, kongesti atau juga waktu proses yang lama. Delay adalah waktu tunda yang dibutuhkan paket data untuk menempuh jarak dari sumber sampai ke tujuan (Al Haris, Simamora, \& Sularsa, 2011). Hal ini dikarenakan adanya antrian yang panjang, atau mengambil rute yang lain untuk menghindari kemacetan. Delay dapat dicari dengan membagi antara panjang paket (between first and last packet (s)) dibagi dengan (packets).

Pengukuran ini bertujuan untuk mengevaluasi delay satu arah pada layanan wireless broadband Flexi melalui jaringan access point satu client ke client lainnya. Merujuk pada rekomendasi bahwa delay yang memenuhi standar atau baik adalah kurang dari $150 \mathrm{~ms}$ (STD A-002-2004 VERSION 1.2). 
Delay dipengaruhi dari lamanya durasi waktu pengiriman paket data. Dari Gambar 4 terlihat bahwa semakin lama durasi waktu maka delay akan semakin menurun, walaupun pada gambar tidak terlihat secara signifikan. Pengujian konektifitas yang dilakukah melalui access point pada modem ADSL, nilai rata-rata delay pada smartphone bernilai $99.04 \mathrm{~ms}$. Sedangkan pada laptop sebesar 56.33 ms. Pengujian konektifitas pada modem GPON, nilai rata-rata delay pada smartphone adalah $97.96 \mathrm{~ms}$ sedangkan pada laptop sebesar $56.15 \mathrm{~ms}$. Berdasarkan hasil pengujian tersebut, maka konektifitas pada modem GPON lebih baik dari modem ADSL. Walaupun demikian, nilai rata-rata delay pada konektifitas modem ADSL masih memenuhi standar yang telah direkomendasikan.

\subsection{Packet Loss}

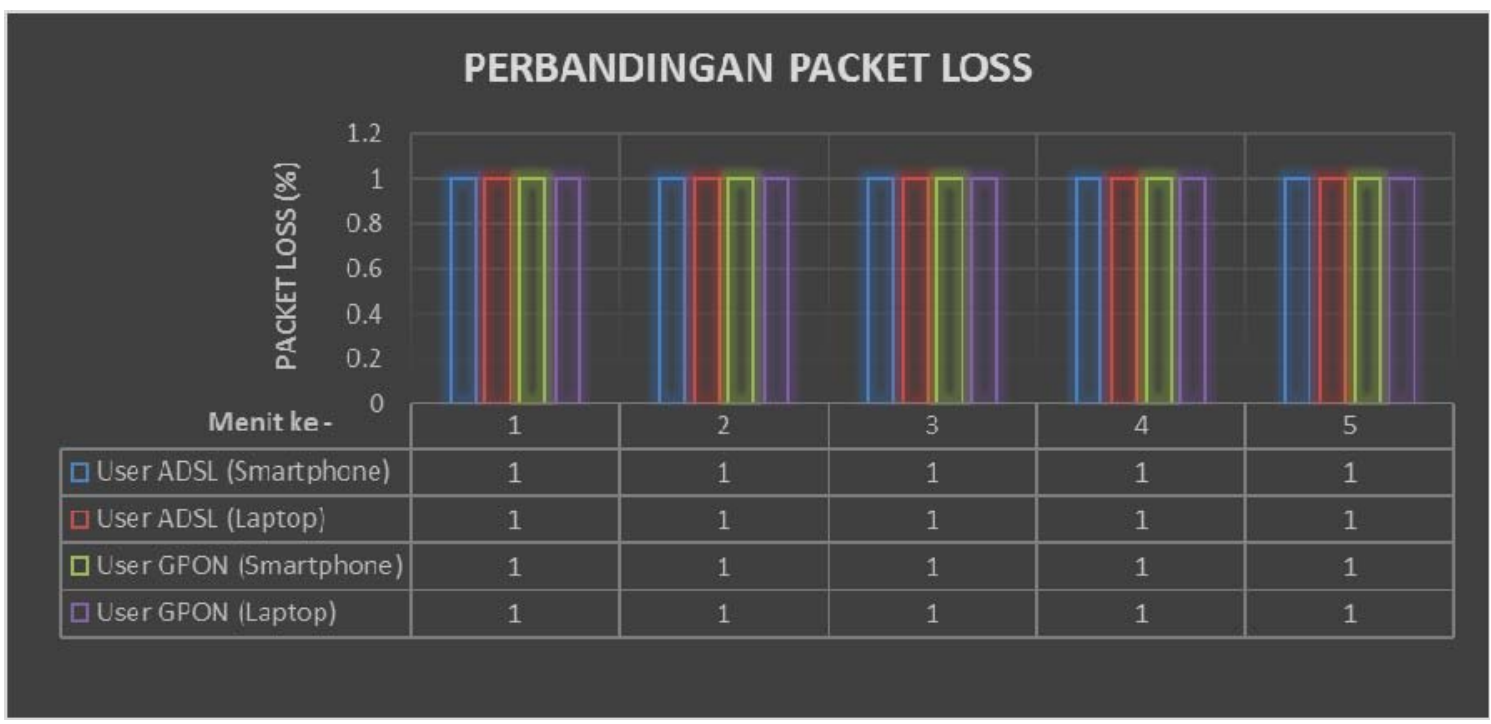

Gambar 5. Perbandingan packet loss

Packet Loss merupakan suatu parameter yang menggambarkan suatu kondisi yang menunjukkan jumlah total paket data yang hilang. Hilangnya paket data dapat terjadi karena collision (tumbukan) dan congestion (antrian) pada jaringan dan hal ini berpengaruh pada semua aplikasi karena jika terjadi proses retransmisi (pengiriman ulang) akan mengurangi efisiensi jaringan secara keseluruhan, meskipun jumlah bandwidth cukup tersedia untuk aplikasi-aplikasi tersebut.

Pengujian ini dilakukan untuk mengetahui berapa besar jumlah paket data yang terkirim pada jaringan dan jumlah paket data yang diterima, maka dalam hal ini akan diukur seberapa besar packet loss yang terjadi pada sistem yang telah dirancang. Berikut ini adalah besarnya packet loss berdasarkan analisis data dari NetTools, yang didapatkan saat pengiriman paket data dari sumber (source) ke tujuan (destination).

Merujuk pada STD A-002-2004 VERSION 1.2 bahwa packet loss memenuhi standar adalah kurang dari 5\%. Seperti ditunjukan pada Gambar 5 diatas, nilai packet loss dari sesama pengguna modem GPON dan ADSL adalah $1 \%$. Arti dari nilai $1 \%$ disini adalah data paket yang dikirim tidak sama dengan data paket yang diterima karena terdapat paket data yang hilang atau rusak. Hal ini terjadi karena jumlah pengguna modem yang terkoneksi dengan access point makin bertambah, sehingga mengalami kepadatan lalu-lintas data. Maka dapat 
dikatakan pengguna modem GPON dan ADSL layak untuk digunakan komunikasi dikarenakan nilai packet loss yang tidak melebihi $5 \%$..

\section{KESI MPULAN}

1. Dari hasil pengujian, jitter yang diperoleh pada performansi modem GPON lebih baik karena nilai rata-rata jitter 45.56 ms, lebih rendah dari pada modem ADSL. Meskipun demikian, rata-rata nilai jitter sebesar $45.6 \mathrm{~ms}$ pada performansi modem ADSL masih memenuhi standar yang telah direkomendasikan, yaitu jitter $\leq 75 \mathrm{~ms}$. Sedangkan nilai jitter untuk smartphone pada performansi modem GPON juga ADSL tidak memenuhi standar yaitu lebih dari $>75 \mathrm{~ms}$.

2. Berdasarkan hasil pengujian delay untuk divais laptop, performansi modem GPON lebih baik karena nilai rata-rata delay 56.15 ms sedikit lebih rendah dari modem ADSL dengan nilai $56.33 \mathrm{~ms}$. Begitu juga pada divais smartphone untuk performansi modem GPON lebih baik karena nilai rata-rata delay sebesar $97.96 \mathrm{~ms}$ dan divais smartphone untuk performansi modem ADSL memiliki nilai rata-rata delay $99.04 \mathrm{~ms}$. Performansi kedua modem memenuhi standar yang telah direkomendasikan, dimana delay yang diperoleh $<150 \mathrm{~ms}$.

3. Berdasarkan hasil pengujian packet loss untuk kategori laptop dan smartphone yang menggunakan modem ADSL maupun modem GPON, keduanya masih berada dalam kategori baik, yaitu memiliki loss sebesar 1\%. Dari kedua modem tersebut tergolong masih memenuhi standar packet loss yaitu $<5 \%$.

4. Implementasi layanan wireless broadband memiliki keuntungan yaitu dapat memuat sampai sebanyak 16 VLAN (Vitual Area Network) dimana masing-masing VLAN memiliki SSID (Service Set Identifier) tersendiri.

5. Dari hasil pengujian QoS secara keseluruhan, pada divais laptop hasil analisis jitter pada modem GPON lebih baik dibanding modem ADSL juga hasil analisis delay pada modem GPON lebih baik dibandingkan dengan modem ADSL. Untuk divais smartphone, nilai delay dan packet loss memenuhi standar yang ditetapkan tetapi tidak untuk nilai jitter.

\section{DAFTAR RUJ UKAN}

Office of Communication. (2005). A Statement on setting quality of service parameters. http://stakeholders.ofcom.org.uk/binaries/consultations/qualitystate/statement/statement. pdf

Tridian. (2010). Perbandingan antara MSAN dan GPON. http://tridrian.wordpress.com/2010/02/16/perbandingan-antara-msan-dan-gpon/

Yulia. (2010). Pengertian jaringan wireless dan komponen pendukungnya. Dipetik Desember 7, 2012, dari Je Mein Yulia: http://jemeinulle.blogspot.com/2010/11/pengertian-jaringanwireless-dan.html

Danang Febianto. (2013). Mari Bicara Tentang GPON, ONU, OLT, DAN ONT. http://kickdanang.wordpress.com/2013/03/31/mari-bicara-tentang-gpon-onu-olt-dan-ontdkk-bagian-1/

Akhmad Mukhammad. (2012). Perangkat-Perangkat Wireless. http://net.comlabs.itb.ac.id/blog/?p=182 